\title{
Medicines for headache before and during pregnancy: a retrospective cohort study (ATENA study)
}

\author{
Chiara Lupi ${ }^{1} \cdot$ Andrea Negro $^{2}$ (i) $\cdot$ Elisabetta Gambassi ${ }^{1} \cdot$ Tommaso Susini $^{3} \cdot$ Pierangelo Geppetti $^{1,4} \cdot$ Silvia Benemei $^{1}$ (D)
}

Received: 7 May 2020 / Accepted: 29 August 2020 / Published online: 23 September 2020

(C) The Author(s) 2020

\begin{abstract}
Objective To investigate headache treatment before and during pregnancy.

Background Most headaches in pregnancy are primary disorders. Headaches are likely to ameliorate during pregnancy, although they may also begin or worsen. Most headache medications should be avoided during pregnancy because of potential fetal risks. However, only scarce evidence on headache drug consumption during pregnancy is available.

Design ATENA was a retrospective, self-administered questionnaire-based, cohort study on women in either pregnancy or who have just delivered and reporting headache before and/or during pregnancy.

Results Out of 271 women in either pregnancy or who have just delivered, $100(37 \%)$ reported headache before and/or during pregnancy and constituted our study sample. Before pregnancy, the attitude toward the use of symptomatic drugs was characterized by both a strong focus on their safety and the willingness to avoid possible dependence from them. Compared to the year before, pregnancy led to changes in behavior and therapeutic habits as shown by a higher proportion of patients looking for information about drugs $(44 / 100$ [44\%] vs. 36/100 [36\%]) and a lower proportion of those treating headache attacks $(88 / 100$ [88\%] vs. 52/100 [52\%]) and by a lower use of nonsteroidal anti-inflammatory drugs (68/100 [68\%] vs. 5/100 [5\%]) and a much higher use of paracetamol (33/100 [33\%] vs. 95/100 [95\%]).

Conclusions Pregnancy changes how women self-treat their headache, and leads to search for information regarding drug safety, mostly due to the perception of fetal risk of drugs. Healthcare providers have to be ready to face particular needs of pregnant women with headache.
\end{abstract}

Keywords Drugs $\cdot$ Headache $\cdot$ Migraine $\cdot$ Cohort study $\cdot$ Pregnancy $\cdot$ Fetal risk

Chiara Lupi, Andrea Negro, and Elisabetta Gambassi equally contributed to this work.

Electronic supplementary material The online version of this article (https://doi.org/10.1007/s10072-020-04702-0) contains supplementary material, which is available to authorized users.

Andrea Negro

andrea.negro@uniroma1.it

1 Headache Centre, Careggi University Hospital, Florence, Italy

2 Regional Referral Headache Centre, Sant'Andrea Hospital, Department of Clinical and Molecular Medicine, Sapienza University, Via di Grottarossa 1035-1039, 00189 Rome, Italy

3 Maternal and Child Department, Careggi University Hospital, Department of Health Sciences, University of Florence, Florence, Italy

4 Department of Health Sciences, University of Florence, Florence, Italy

\author{
Abbreviations \\ NRS Numeric rating scale \\ NSAIDs Nonsteroidal anti-inflammatory drugs
}

\section{Background}

Headache is a common symptom in women, affecting almost $20 \%$ of female general population as a primary disorder [1]. The occurrence of headache is influenced by female hormonal changes throughout the life cycle [2], and a large portion of pregnant women refers primary headaches, including tensiontype headache and migraine [3]. Although the gestation, mainly during the last two trimesters, is usually associated with a decrease of attack frequency and severity in migraineurs $[4$, 5], 4-8\% of patients report a worsening of symptoms and, in some subjects, migraine appears for the first time in the first 
trimester of pregnancy [6]. Several critical issues affect the management of headache, and particularly migraine, in pregnancy. On the one hand, migraine per se is a risk factor for gestational complications, such as hypertension, preeclampsia, and ischemic stroke [7], and it can lead to impaired nutritional intake, dehydration, sleep deprivation, high stress, and depression with associated adverse events on maternal and fetal well-being, when untreated or poorly managed [8]. On the other hand, the consumption of medications, with proven or unknown teratogenic potential, to treat $[9,10]$ or prevent [11-13] headache attacks can result in fetal malformations. Paracetamol, the recommended acute treatment for migraine attacks during pregnancy, has been associated, on long-term use, with adverse neurodevelopmental outcomes [14], attention deficit hyperactivity disorder [15, 16], and hyperkinetic disorders [15] in children. Furthermore, a meta-analysis recently confirmed the association between the prenatal paracetamol exposure and the increased risk of child asthma [17]. In another meta-analysis which compared triptan-exposed women with the healthy controls during pregnancy, a significant increase in the rates of spontaneous abortions was found, while no increased risk of fetal malformations or prematurity was detected [18].

Notwithstanding the high prevalence of headache in women with childbearing potential [19], hence candidate to drug consumption during pregnancy, evidence about the safety of headache medication use during gestation is still limited. It is worth noting that most patients are not aware of the multifaceted risks due to migraine during pregnancy mentioned above: risks directly linked to the disease, risks due to its inappropriate treatment, and risks associated with headache medications [20]. In a Norwegian cross-sectional Internet-based survey [21], the majority of pregnant women and new mothers with migraine reported the intake of symptomatic medications during pregnancy, with a decreased use of triptans and nonsteroidal antiinflammatory drugs (NSAIDs) in favor of paracetamol compared to the pregestational age, yet less than a third considered their headache to be optimally treated. Many women were concerned about whether it was safe to continue drug treatment during pregnancy and sought information about their medications [21]. Data about headache presentation and its treatment in pregnancy have never been collected in the Italian population. In this scenario, we aimed to investigate headache before and/or during pregnancy in a cohort of women, focusing on its pharmacological treatment, in terms of attitude on drug use, need of information on medications, and perception of the possible risks to the fetus deriving from drug consumption.

\section{Methods}

We performed a retrospective cohort study with crosssectional collection of data by convenience sampling of treatment-seeking individuals. From July 12, 2017, to September 2, 2017, women ( $\geq 18$ years old) either in the last period of pregnancy (i.e., while they were admitted for planned delivery) or who have delivered in the previous 7 days were screened at the Maternal and Child Department, Careggi University Hospital, for enrolment in the study. Women who reported a diagnosis of secondary headaches, according to the International Classification of Headache Disorders 3rd edition (ICHD-3) [22], were not considered eligible to the study. Patients who reported having experienced headache before and/or during pregnancy were asked for filling a self-administered questionnaire, translated and adapted from Amundsen et al. [21]. The questionnaire was constituted by seven main sections: personal information, pregnancy information, headache history, headache presentation and medications before and during pregnancy, attitude toward use of headache medications before and during pregnancy, perception of fetal risk of drugs and substances during pregnancy, and research of information on headache medications before and during pregnancy (Table 1). We adapted and translated in Italian the Amundsen's questionnaire (Supplementary Materials) in order to administer it to Italian-speaking participants.

According to the descriptive aim of the study, no formal sample size calculation has been performed. The answers reported by the patients in the paper version of the questionnaire were transferred to an electronic database and analyzed by descriptive statistics (e.g., proportions and percentages for quantitative and categorical variables; mean $\pm \mathrm{SD}$ or median and interquartile range (IQR) for continuous variables). The analysis was performed using Prism, 8.3.1 (GraphPad Software, San Diego, CA, USA). The participants were asked to express their opinion about headache medicine and substance consumption in pregnancy, in terms of perception of risk to the fetus, on a risk scale (from 0 ["not harmful"] to 10 ["very harmful"]). For analysis purposes, values ranging from 0 to 3 were considered as "low risk," values from 4 to 6 were considered as "intermediate risk," and values from 7 to 10 were considered as "high risk." Original data are available on request from the authors.

\section{Results}

\section{Study population}

One hundred thirty-nine (51\%) out of 271 screened women referred a history of headache, prior to and/or during pregnancy. One hundred women (37\% of 271) signed the informed consent and participated in the study. Results are reported with detailed information about numbers and percentages of participants who gave answers. Numbers and percentages of patients that did not answer to each question, as they are low and 
Table 1 Original questionnaire from Amundsen et al. [21]

Which of this holds true for you? If you are both pregnant and have previous children, please tick "I am pregnant"

I am pregnant $\bigcirc \mathrm{I}$ am a mother

\section{Personal information}

First, we would like to ask you some personal questions. Your answers will provide us with some background information, which will make study interpretation easier. It will not be possible to identify you from your given answers.

Year of birth (year in yyyy)?

Marital status

$\bigcirc$ Married $\bigcirc$ In a relationship $\bigcirc$ single $\bigcirc$ Other

In which county do you live?

$\bigcirc$ Akershus $\bigcirc$ Aust-Agder $\bigcirc$ Buskerud $\bigcirc$ Finnmark $\bigcirc$ Hedmark $\bigcirc$ Hordaland $\bigcirc$ Møre og Romsdal $\bigcirc$ NordTrøndelag $\bigcirc$ Nordland $\bigcirc$ Oppland $\bigcirc$ Oslo $\bigcirc$ Rogaland $\bigcirc$ Sogn og Fjordane $\bigcirc$ Sør-Trøndelag $\bigcirc$ Telemark $\bigcirc$ Troms $\bigcirc$ Vest-Agder $\bigcirc$ Vestfold $\bigcirc$ østfold $\bigcirc$ Abroad $\bigcirc$ Other

\section{Profession/Employment situation}

$\bigcirc$ Student $\bigcirc$ Employed (check here even if you are currently on sick leave) $\bigcirc$ Housewife

Maternity leave $\bigcirc$ Other

\section{Highest educational level}

$\bigcirc$ Primary school $\bigcirc$ Secondary/High school $\bigcirc$ 1-4 years in College/University $\bigcirc \geq 5$ years in College/University Other

If other, please specify:

If you are in employment, have you been on sick leave during your pregnancy due to migraine? 
Table 1 (continued)

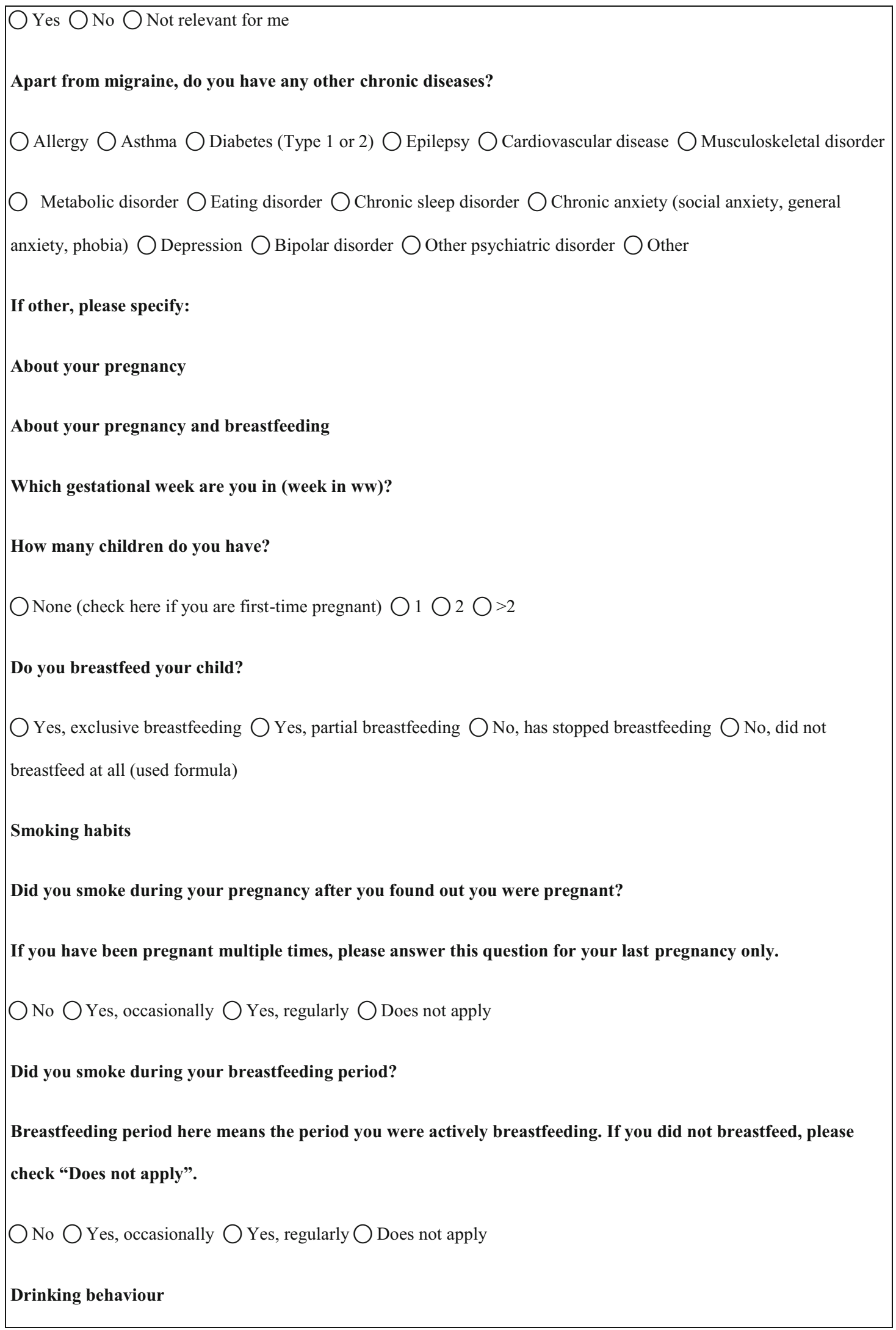


Table 1 (continued)

Did you consume alcohol during your pregnancy after you found out you were pregnant? If yes, please indicate

the consumed units.

One unit of alcohol corresponds to 1 glass of wine $(15 \mathrm{cL}), 1$ bottle $(33 \mathrm{cL})$ of beer/alcopops, one shot glass $(2 \mathrm{cL})$ of liquor. If you have been pregnant multiple times, please answer this question for your last pregnancy only.

I did not drink at all $\bigcirc$ Fewer than 2 units per month $\bigcirc$ 1-2 units per month $\bigcirc 1-2$ units per week $\bigcirc$ More than 2 units per week $\bigcirc$ I do not remember

Did you consume alcohol during your breastfeeding period?

Breastfeeding period here means the period you were actively breastfeeding. If you did not breastfeed, please check "Does not apply".

One unit of alcohol corresponds to 1 glass of wine $(15 \mathrm{cL}), 1$ bottle $(33 \mathrm{cL})$ of beer/alcopops, one shot glass (2cL) of liquor.

I did not drink at all $\bigcirc$ Fewer than 2 units per month $\bigcirc$ 1-2 units per month $\bigcirc 1-2$ units per week $\bigcirc$ More than 2 units per week $\bigcirc$ I do not remember $\bigcirc$ Does not apply

can be easily inferred knowing numbers and percentages of participants who gave answers, are not detailed in the text unless they are relevant to the discussion.

\section{Personal information}

Personal information of the study population included age, marital status, status of employment, highest level of education, sick leave during pregnancy due to headache, and chronic illnesses. This information was categorized and is reported in Table 2 .

\section{Pregnancy information}

At the time of completion of the questionnaire, 77 participants (77\%) referred they had delivered in the previous 7 days, and $22(22 \%)$ referred they were pregnant (gestational age $37.3 \pm$ 4.2 weeks). Fifty-four women (54\%) reported to have already a child, 21 (21\%) two children, and 10 (10\%) more than two children. Fourteen women (14\%) referred they were at their first pregnancy.

Ten participants $(10 \%)$ referred they had smoked during pregnancy, occasionally (9 participants) or regularly (1 participant). Sixty-three women $(63 \%)$ reported they did not have smoked during gestation, and $27(27 \%)$ reported they were not smokers even before pregnancy (Fig. 1).

In terms of alcohol use during pregnancy, 78 participants (78\%) reported no alcohol consumption, while 21 (21\%) reported alcohol use (Fig. 1).

\section{Headache history}

Headache onset was reported to be, on average, at the age of $17.3 \pm 6.3$ by 90 women (90\%); 10 women did not refer any information about that. Eighty-seven women (87\%) referred headache attacks in the latest year before pregnancy. Twenty women reported they had received a headache diagnosis before pregnancy, including migraine ( $n=8$ migraine without aura, $n=7$ migraine with aura), tension-type headache $(n=3)$, 
Table 1 (continued)

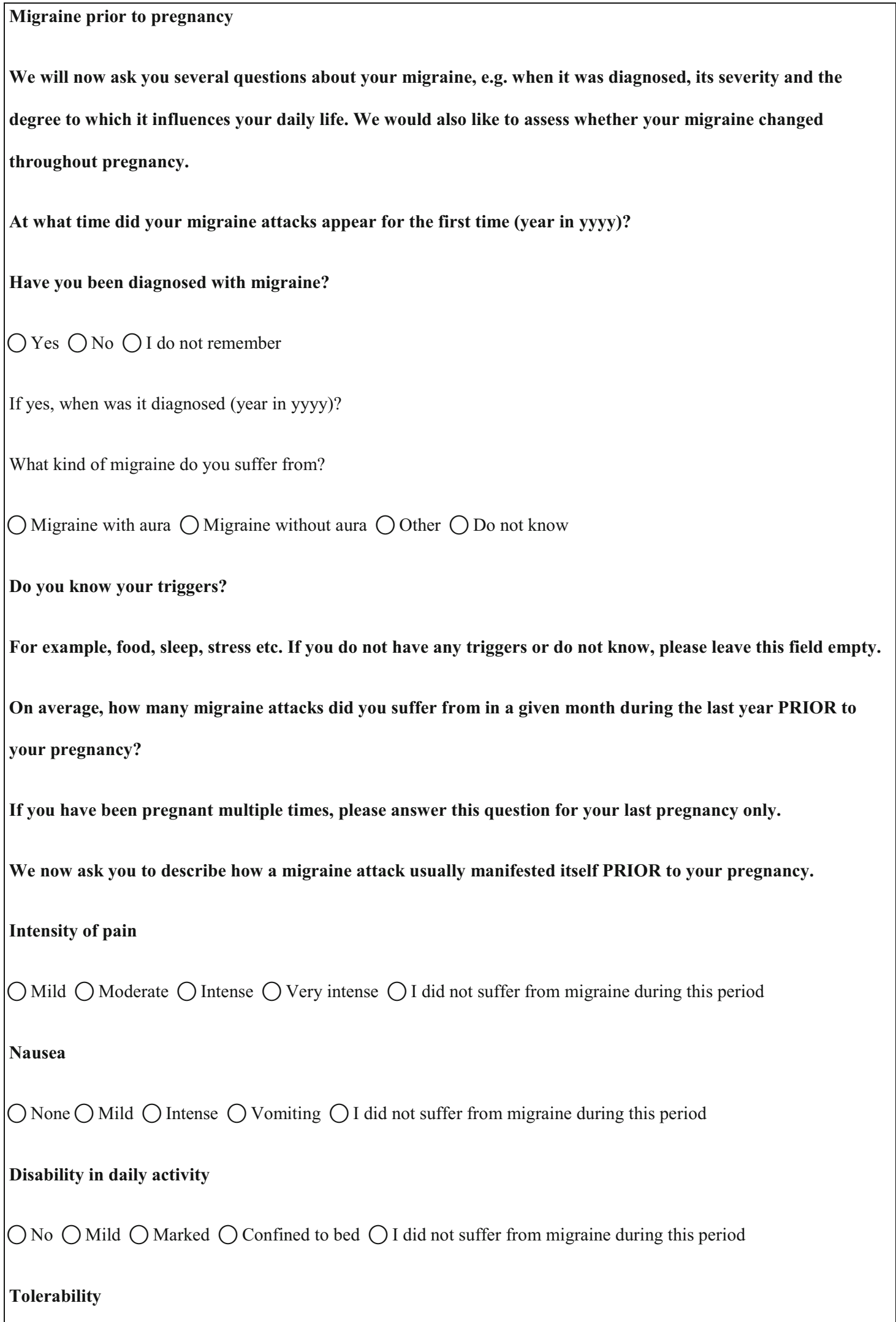


Table 1 (continued)

$\bigcirc$ Tolerable $\bigcirc$ Barely tolerable $\bigcirc$ Intolerable $\bigcirc$ I did not suffer from migraine during this period

Migraine during pregnancy

If you have been pregnant multiple times, please answer this question for your last pregnancy only.

On average, how many migraine attacks did you suffer from in a given month during the FIRST TRIMESTER of your pregnancy?

First trimester describes the first three months of your pregnancy.

On average, how many migraine attacks did you suffer from in a given month during the SECOND

TRIMESTER of your pregnancy?

Second trimester describes months 4-6 of your pregnancy. If you are currently pregnant and have not reached the second trimester, please fill in a dash "_.".

On average, how many migraine attacks did you suffer from in a given month during the THIRD TRIMESTER of your pregnancy?

Third trimester describes months 7-9 of your pregnancy. If you are currently pregnant and have not reached the third trimester, please fill in a dash "__“.

We now ask you to describe how a migraine attack usually manifested itself DURING your pregnancy.

Intensity of pain

$\bigcirc$ mild $\bigcirc$ Moderate $\bigcirc$ Intense $\bigcirc$ Very intense $\bigcirc$ I did not suffer from migraine during this period

Nausea

$\bigcirc$ None $\bigcirc$ Mild $\bigcirc$ Intense $\bigcirc$ vomiting $\bigcirc$ I did not suffer from migraine during this period

Disability in daily activity

$\bigcirc$ No $\bigcirc$ Mild $\bigcirc$ Marked $\bigcirc$ confined to bed $\bigcirc$ I did not suffer from migraine during this period

Tolerability 
Table 1 (continued)

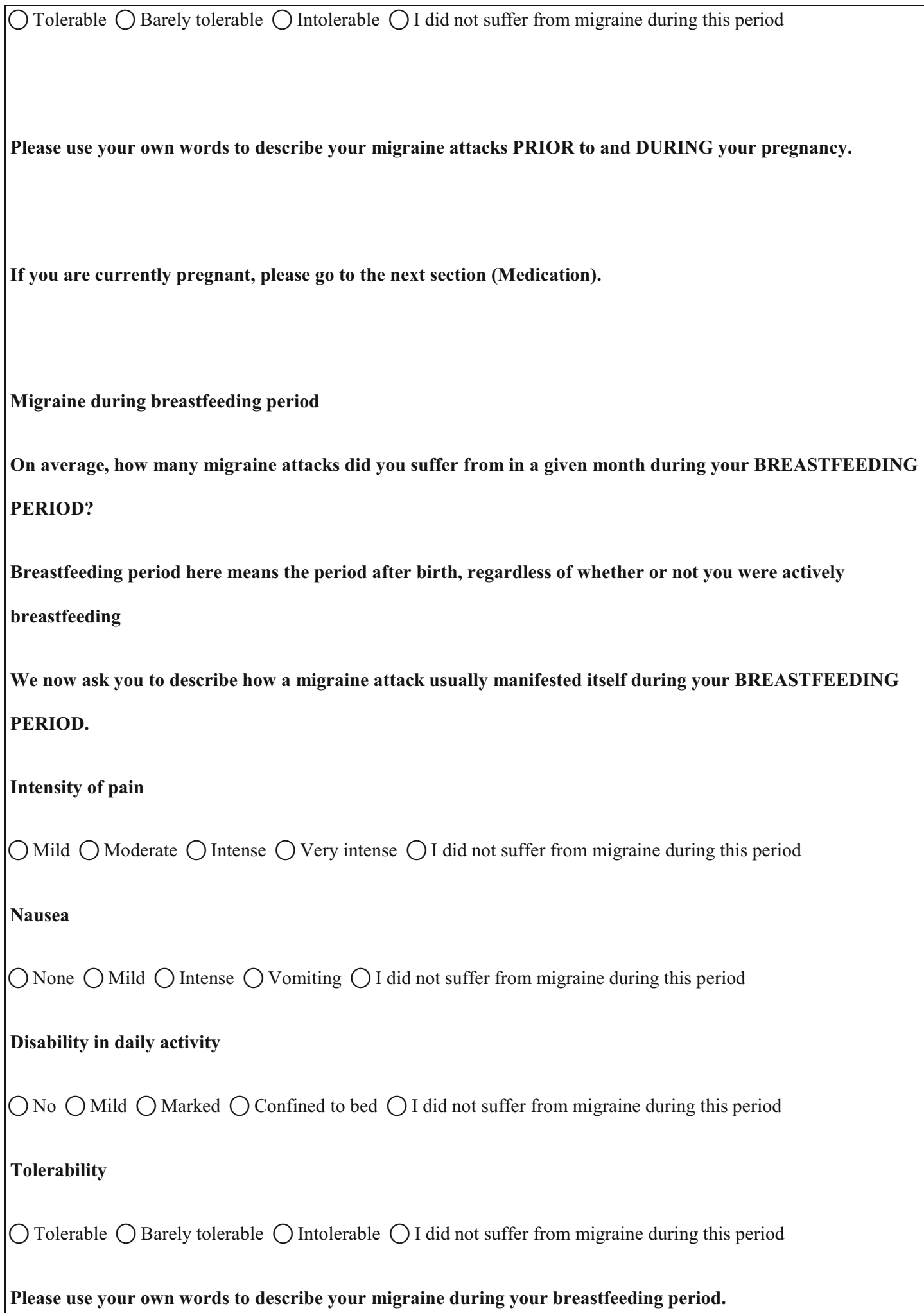


Table 1 (continued)

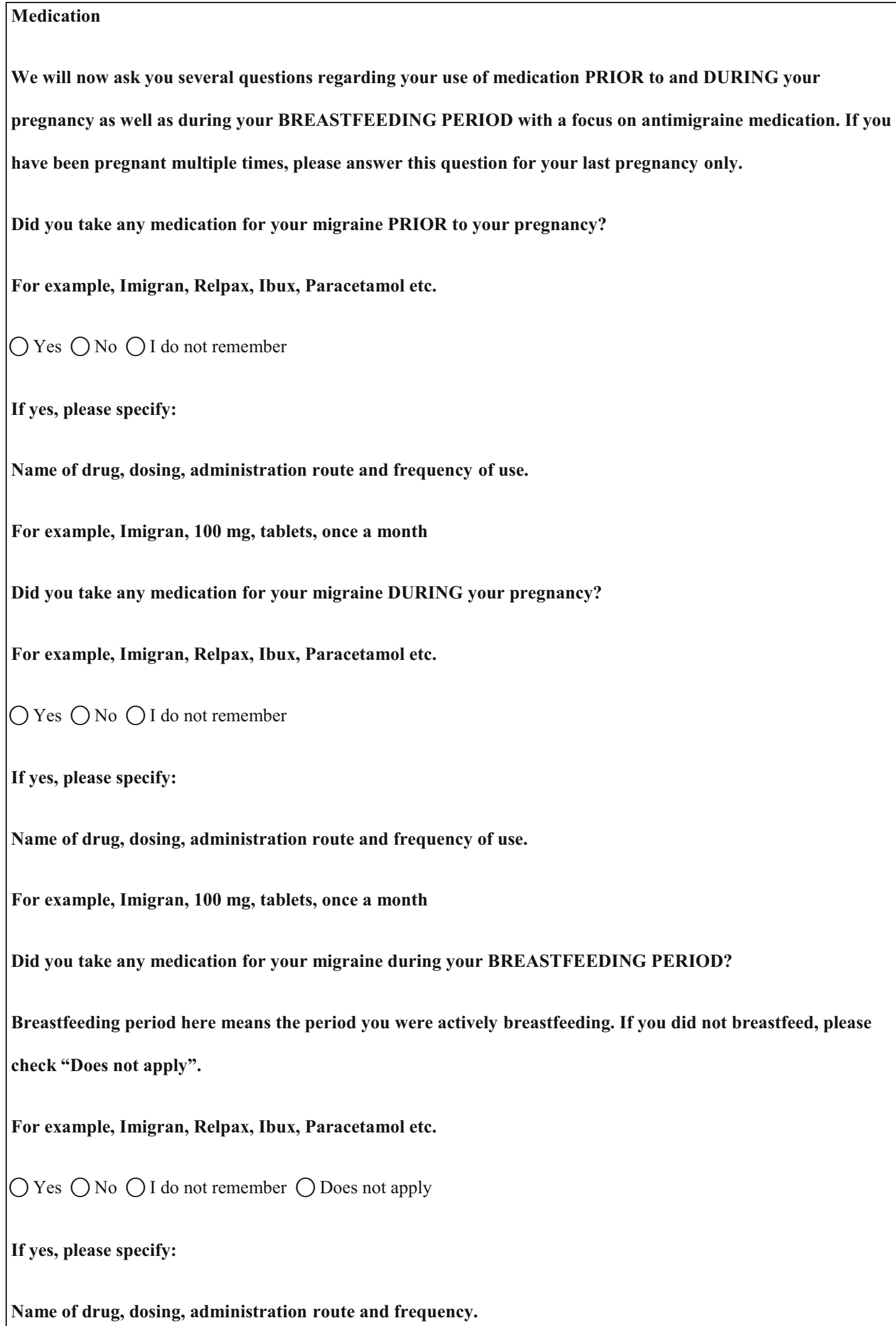


Table 1 (continued)

For example, Imigran, 100mg, tablets, once a month

If you have taken medication for your migraine, please check the boxes in the following table. In case you have taken multiple drugs, please check multiple boxes.

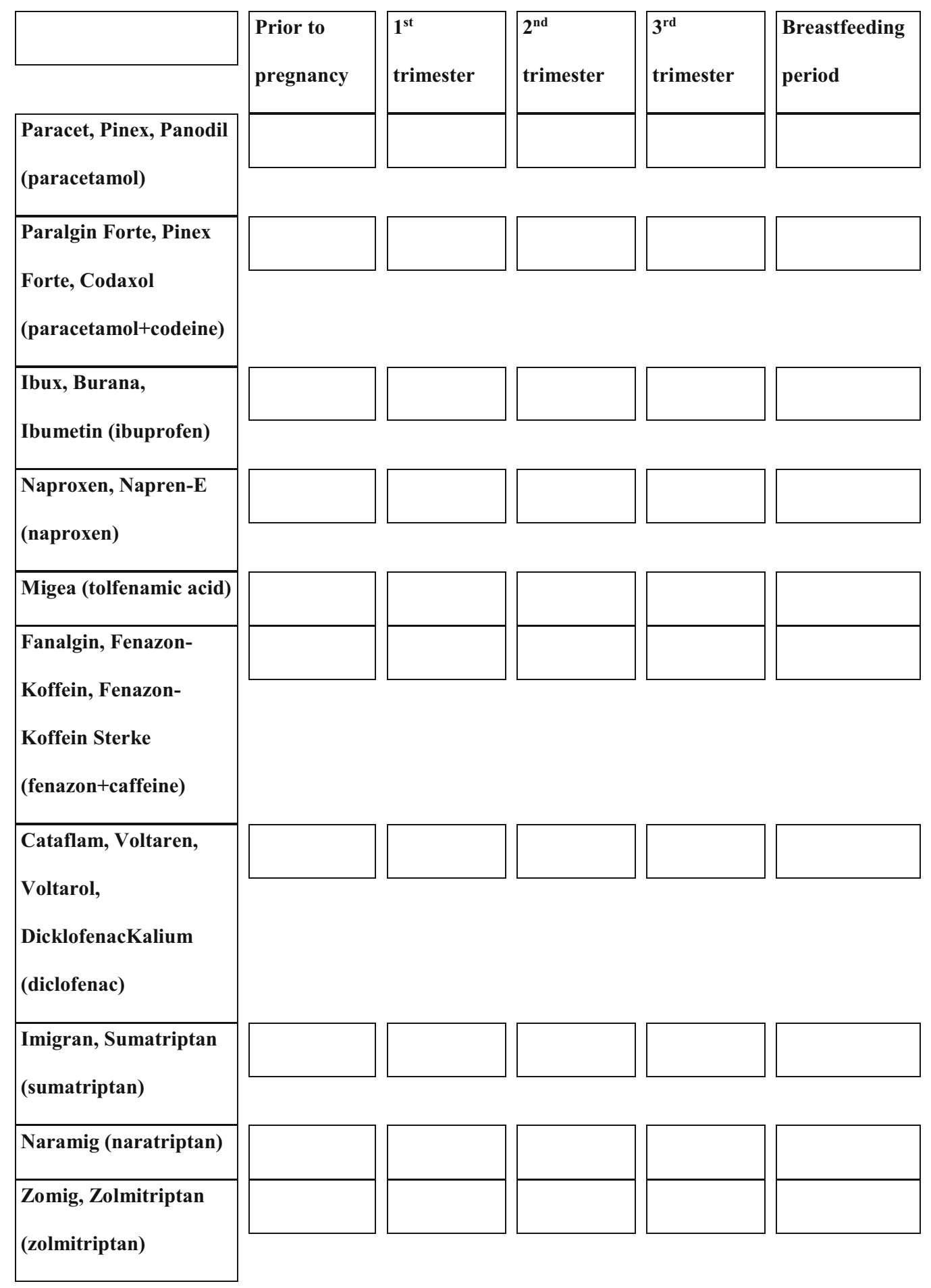


Table 1 (continued)

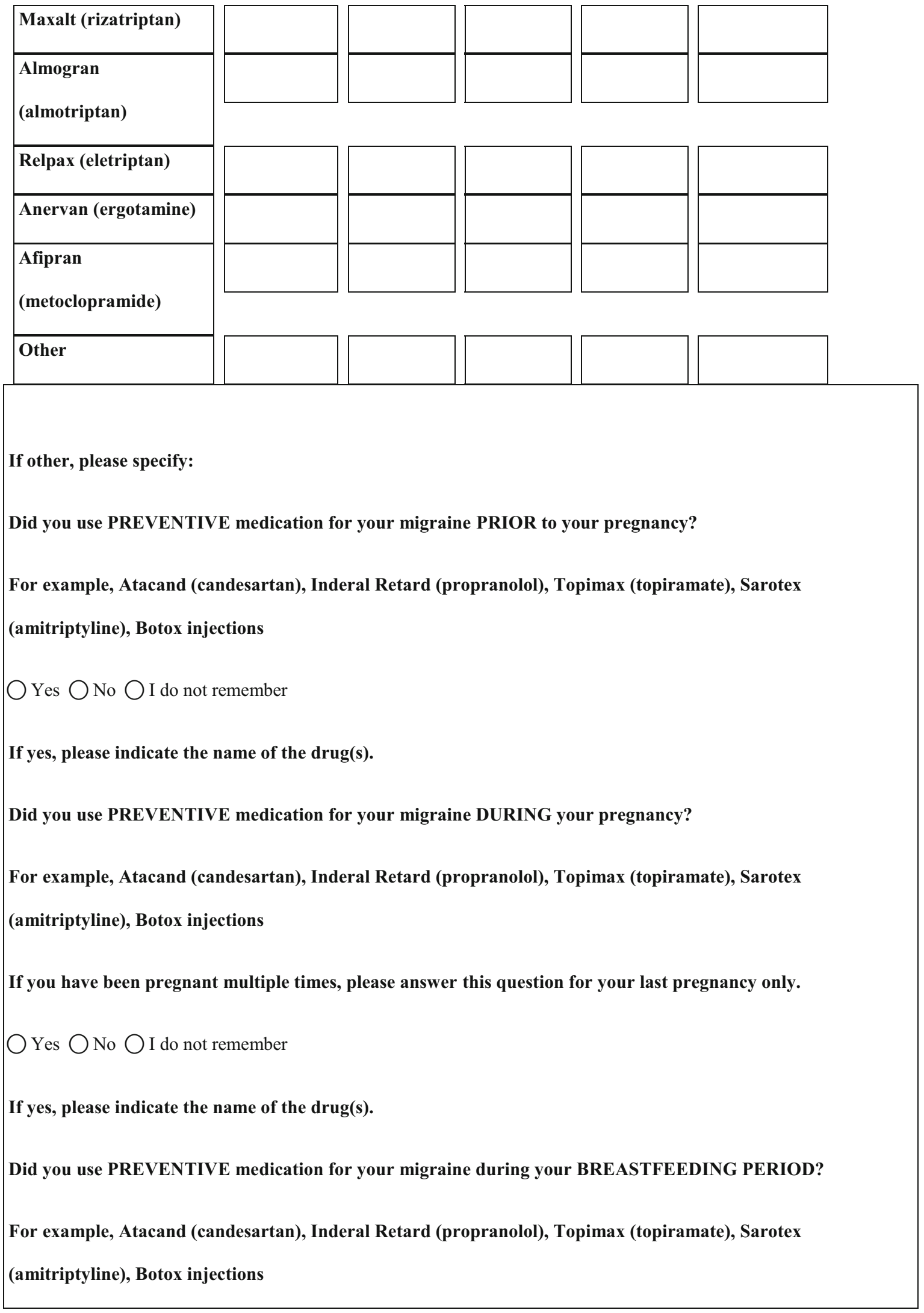


Table 1 (continued)

Breastfeeding period here means the period you were actively breastfeeding. If you did not breastfeed, please
tick "Does not apply".
Yes $\bigcirc$ No $\bigcirc$ I do not remember $\bigcirc$ Does not apply
If yes, please indicate the name of the drug(s).
Have you taken any of the following?

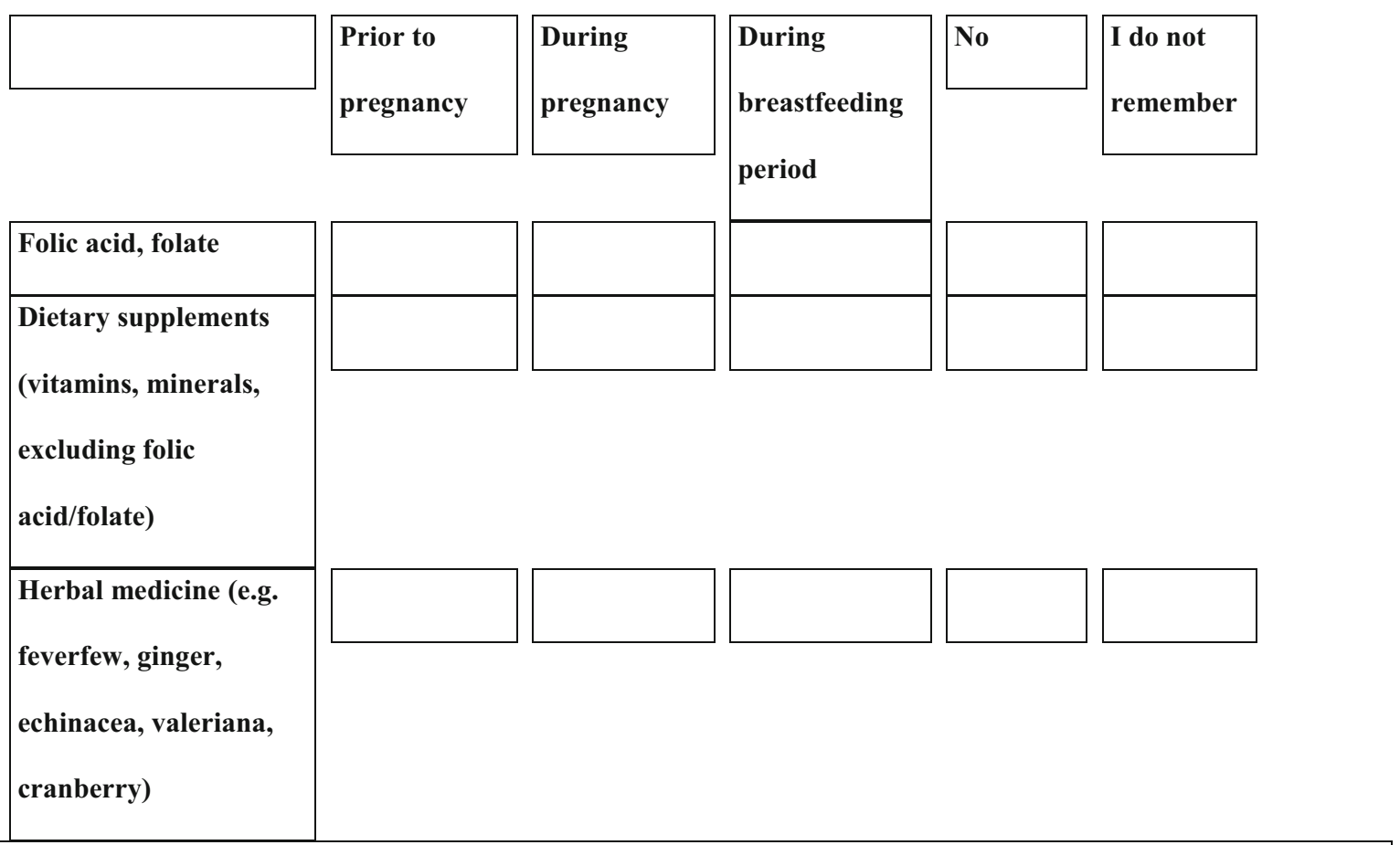

If you checked any boxes above, please specify

Name of medication and when it was taken. When refers to prior to or during pregnancy or during breastfeeding.

Have you used any other medication that the ones mentioned above, including over-the-counter (OTC) drugs?

If you did not breastfeed, please check "Does not apply".

\begin{tabular}{|l|l|l|l|l|l|l|l|}
\hline Yes & No do not remember & Does not apply \\
\hline Prior to pregnancy & & \\
\hline
\end{tabular}


Table 1 (continued)

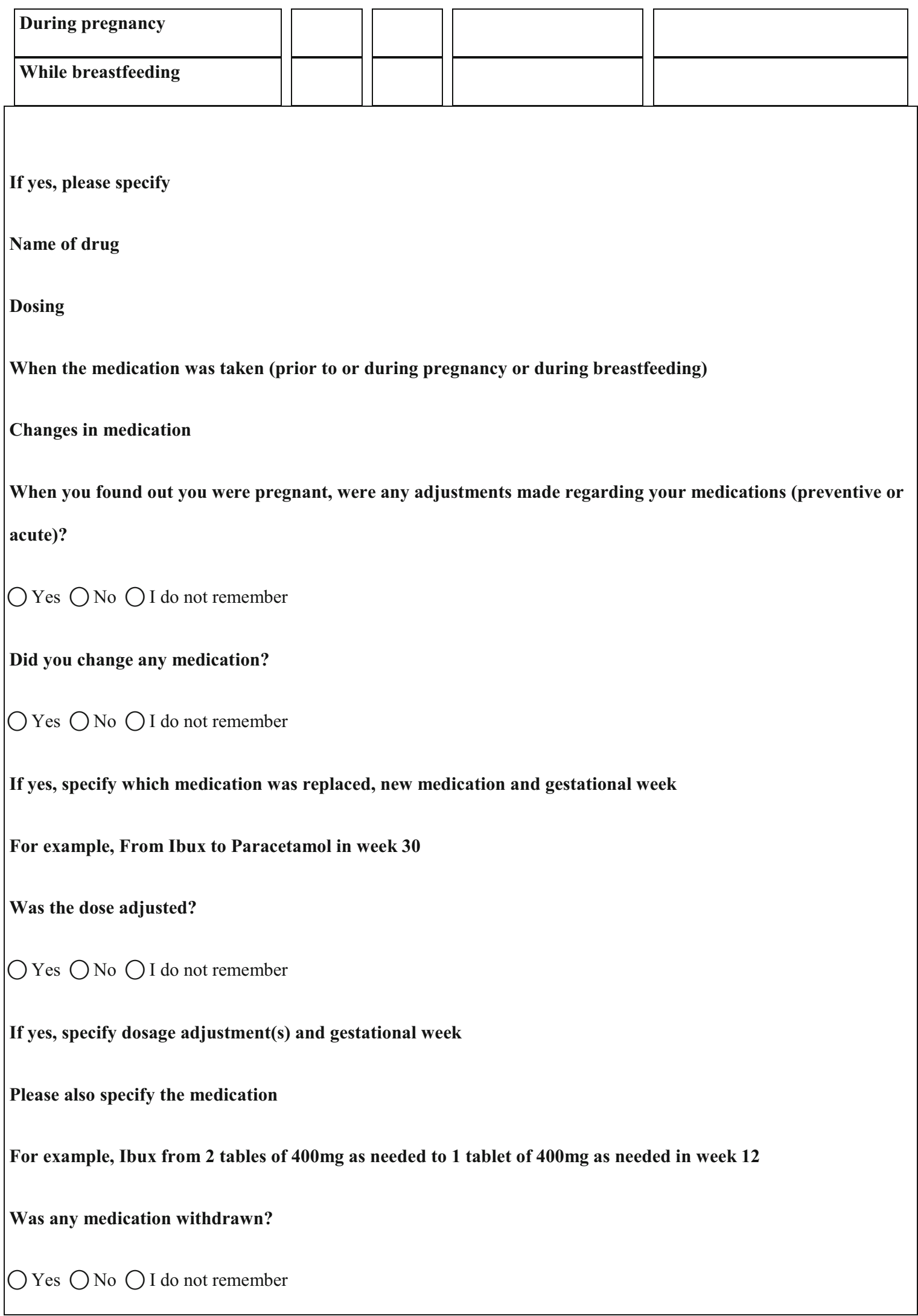


Table 1 (continued)
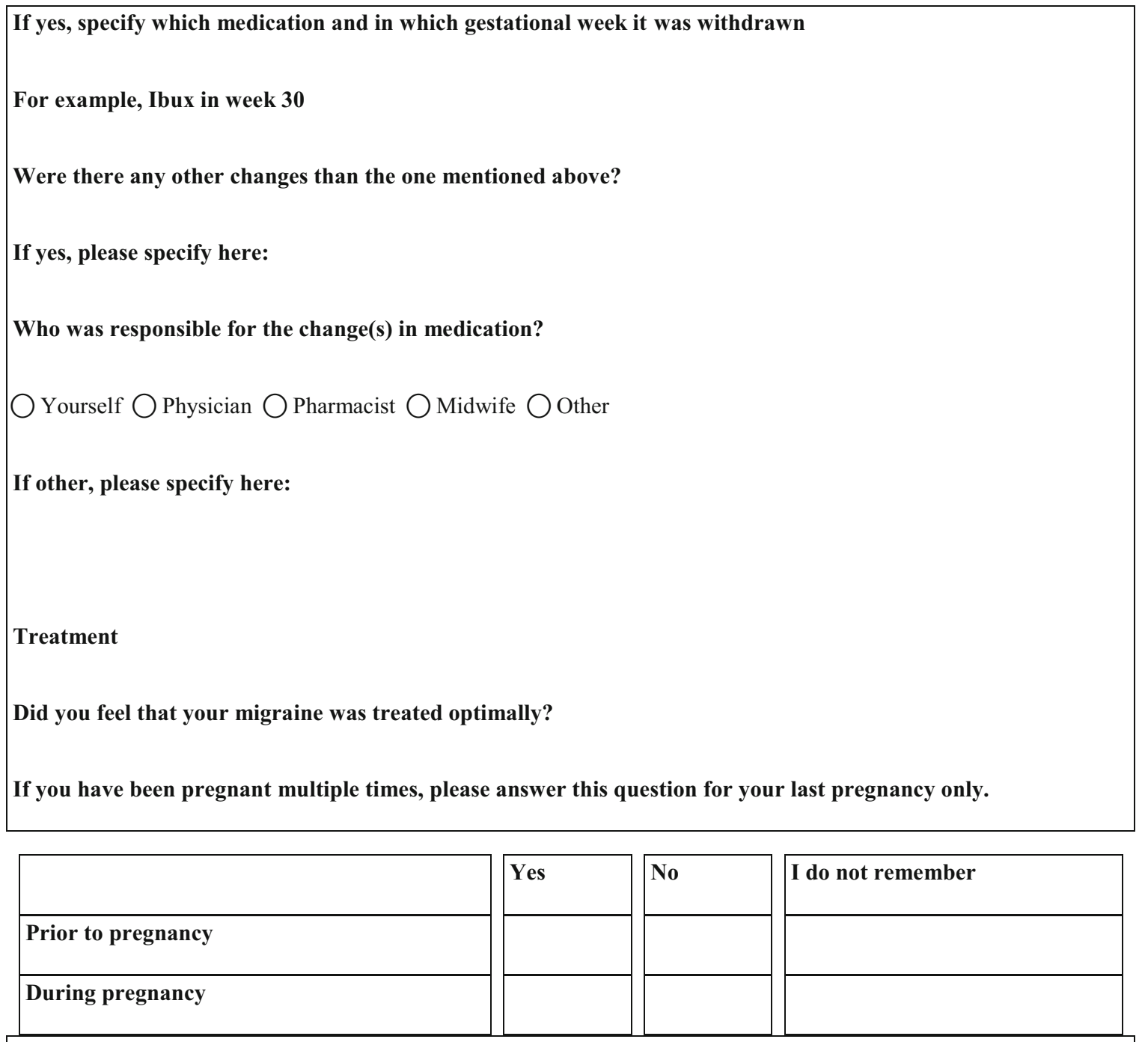

Breastfeeding period here means the period after birth, regardless of whether or not you were actively breastfeeding.

\begin{tabular}{|c|c|c|c|}
\hline & Yes & No & I do not remember \\
\hline Prior to pregnancy & & & \\
\hline During pregnancy & & & \\
\hline During your breastfeeding period & & & \\
\hline
\end{tabular}

Who is responsible for the medical treatment of your migraine? 
Table 1 (continued)

$\bigcirc$ Physician/General practitioner $\bigcirc$ Migraine specialist $\bigcirc$ Other $\bigcirc$ I am not taking any medication

If other, please specify here:

Have you tried any of the following treatment options for your migraine?

$\bigcirc$ Acupuncture $\bigcirc$ Homeopathy $\bigcirc$ Physiotherapy $\bigcirc$ chiropractic $\bigcirc$ Physical exercise (including yoga, pilates or similar) $\bigcirc$ Foot zone therapy $\bigcirc$ Other $\bigcirc$ Not relevant

\section{Your attitudes on the use of antimigraine medications}

Here we would like to know some of your personal opinions and views on your prescribed medications. You will be shown statements given by other people on their respective medications. Please indicate to which degree you agree or disagree with these statements.

\begin{tabular}{|c|c|c|c|c|c|}
\hline & Strongly & Agree & Uncertain & Disagree & \multirow{2}{*}{$\begin{array}{l}\text { Strongly } \\
\text { disagree }\end{array}$} \\
\hline & agree & & & & \\
\hline \multicolumn{6}{|l|}{ My health, at present, depends on my medicines } \\
\hline \multicolumn{6}{|l|}{ Having to take medicines worries me } \\
\hline \multicolumn{6}{|l|}{ My life would be impossible without my } \\
\hline \multicolumn{6}{|l|}{ medicines } \\
\hline \multicolumn{6}{|l|}{ I sometimes worry about the long-term effects of } \\
\hline \multicolumn{6}{|l|}{ my medicines } \\
\hline \multicolumn{6}{|l|}{ Without my medicines I would be very ill } \\
\hline \multicolumn{6}{|l|}{ My medicines are a mystery to me } \\
\hline \multicolumn{6}{|l|}{ My health in the future will depend on my } \\
\hline \multicolumn{6}{|l|}{ medicines } \\
\hline \multicolumn{6}{|l|}{ My medicines disrupt my life } \\
\hline \multicolumn{6}{|l|}{ I sometimes worry about becoming too dependent } \\
\hline on my medicines & & & & & \\
\hline My medicines protect me from becoming worse & & & & & \\
\hline
\end{tabular}


Table 1 (continued)

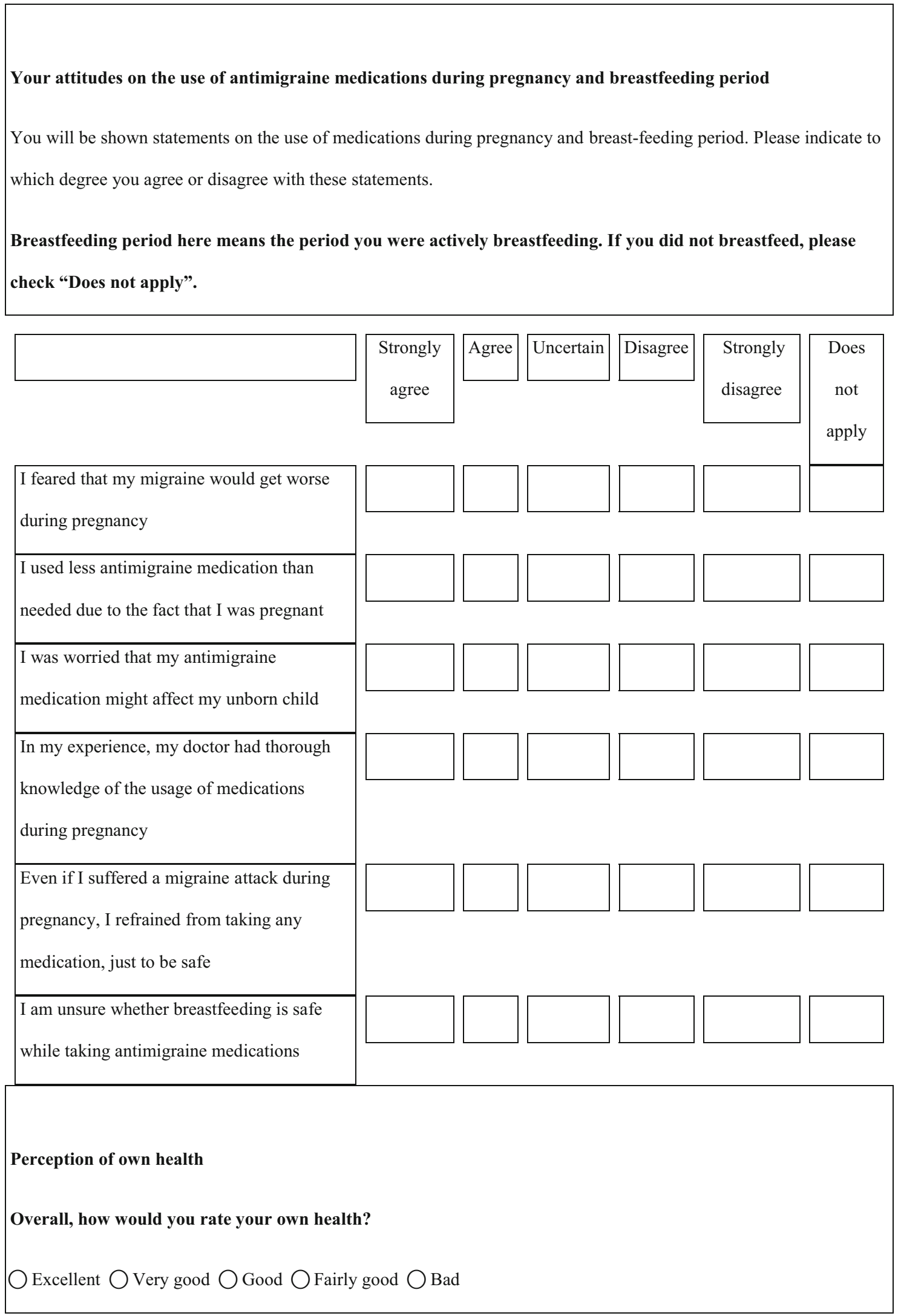


Table 1 (continued)

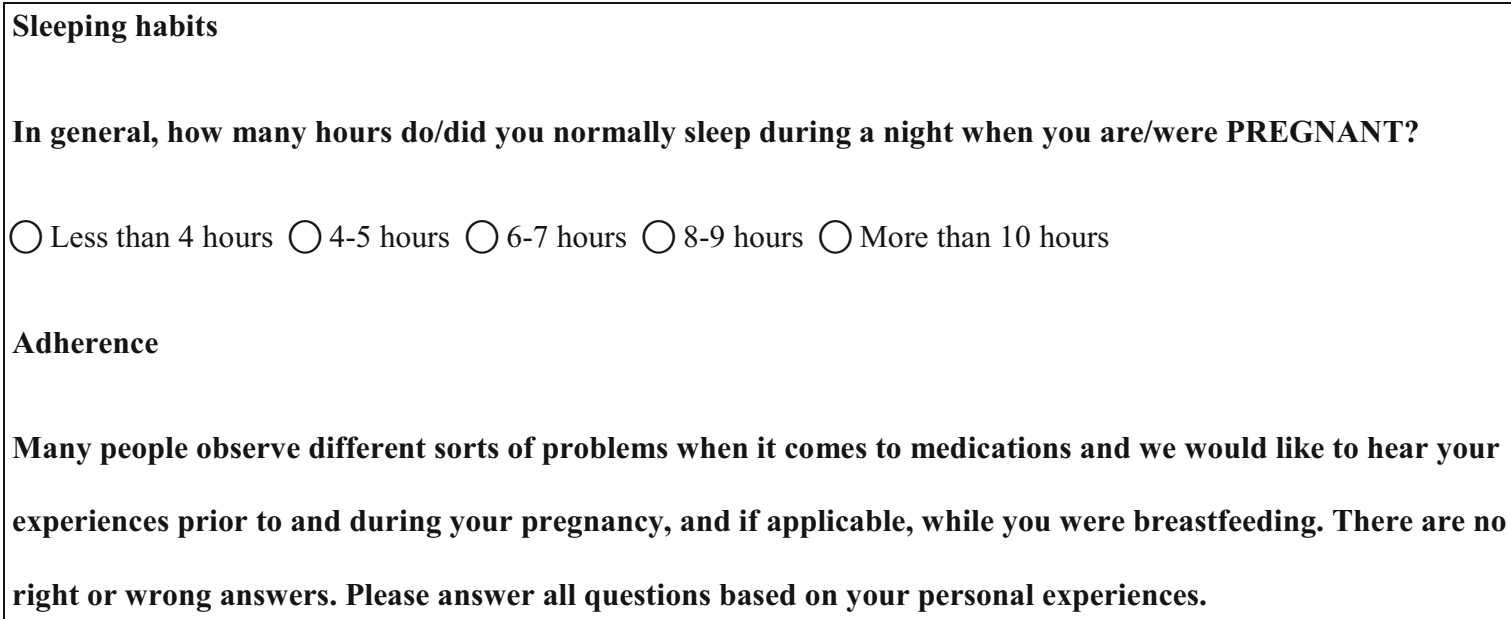

This applies both to preventive and acute medication.

$\bigcirc$ Yes $\bigcirc$ No $\bigcirc$ i do not remember

If you answered yes, please specify the medication(s)

If you answered yes, please specify the reason(s)

Has it ever happened that you have deliberately not taken your prescribed medications because you were breastfeeding?

This applies both to preventive and acute medication.

$\bigcirc$ Yes $\bigcirc$ No $\bigcirc$ I do not remember $\bigcirc$ I did not breastfeed, does not apply

If you answered yes, please specify the medication(s)

If you answered yes, please specify the reason(s)

Risk perception 
Table 1 (continued)

\begin{abstract}
Many pregnant and breastfeeding women are concerned about whether the use of medications during pregnancy and/or breastfeeding period might affect their unborn child. With the following questions, we would like to get an idea of how you perceive the following risks.

Among 100 healthy pregnant women, how many do you think will give birth to a child with severe birth defects?

Risk scale during pregnancy

You will now be presented a list of various medications, drugs and other substances. On a scale from 0 to 10 , where 0 is "not harmful" and 10 is "very harmful", please indicate how harmful you think these substances are for an unborn child? If you do not know the substance, please check "I do not know".
\end{abstract}

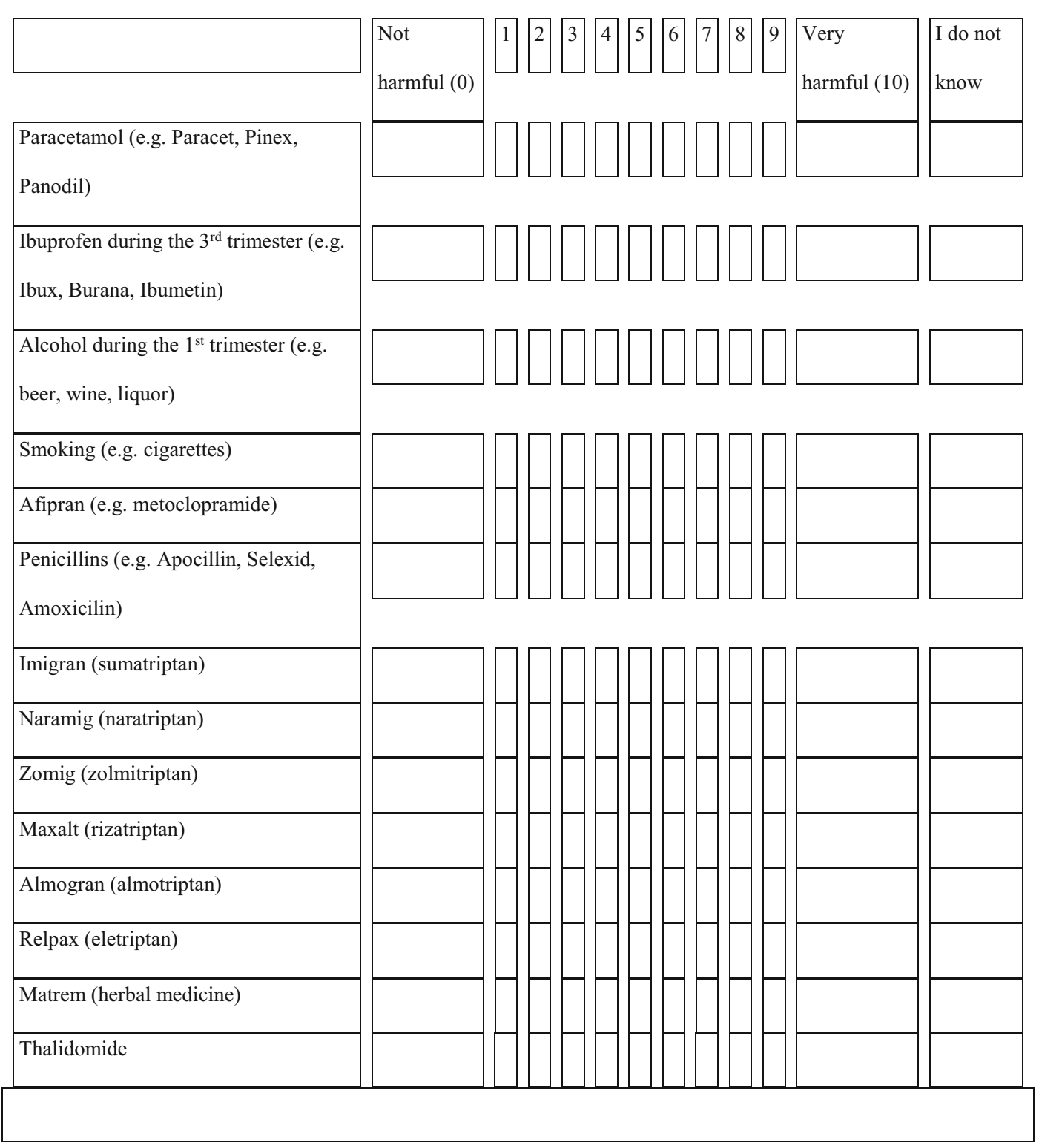


Table 1 (continued)

Information

Now we would like to assess your needs regarding information about medications, especially antimigraine medications. We would like to assess which sources you primarily receive your information from and what kind of experiences you have made with different sources.

Prior to your pregnancy

Did you require information about antimigraine medications PRIOR to your pregnancy?

$\bigcirc$ Yes $\bigcirc$ No $\bigcirc \mathrm{I}$ do not remember

If yes, which source(s) did you use PRIOR to your pregnancy? If applicable, check several sources.

$\bigcirc$ Internet $\bigcirc$ Friends/family $\bigcirc$ Physician $\bigcirc$ Pharmacy $\bigcirc$ Package information leaflet $\bigcirc$ Midwife $\bigcirc$ other $\bigcirc$ Does not apply

If you checked Internet or Others - please specify here:

During your pregnancy

Did you require information about antimigraine medications DURING your pregnancy?

$\bigcirc$ Yes $\bigcirc$ No $\bigcirc$ d do not remember

If yes, which source(s) did you use DURING your pregnancy? If applicable, check several sources.

$\bigcirc$ Internet $\bigcirc$ Friends/family $\bigcirc$ Physician $\bigcirc$ Pharmacy $\bigcirc$ Package information leaflet $\bigcirc$ Midwife $\bigcirc$ other $\bigcirc$ Does not apply

If you checked Internet or Others - please specify here:

During breastfeeding period

Breastfeeding period here means the period you were actively breastfeeding. If you did not breastfeed, please check "Does not apply".

Did you require information about antimigraine medications while BREASTFEEDING? 
Table 1 (continued)

$\bigcirc$ Yes $\bigcirc$ No $\bigcirc$ I do not remember $\bigcirc$ Does not apply

If yes, which source(s) did you use while BREASTFEEDING? If applicable, check several sources.

$\bigcirc$ Internet $\bigcirc$ Friends/family $\bigcirc$ physician $\bigcirc$ Pharmacy $\bigcirc$ Package information leaflet $\bigcirc$ Midwife $\bigcirc$ Other $\bigcirc$

Does not apply

If you checked Internet or Others - please specify here:

If you used multiple sources, did you experience that the information provided was similar?

$\bigcirc$ Does not apply $\bigcirc$ Yes, the information was identical. $\bigcirc$ Yes, the information was more or less identical (minor variations in speech or details). $\bigcirc$ No, the information provided was partly different. $\bigcirc$ No, the information provided was contradictory.

If the information provided from different sources were not similar, what did you do?

$\bigcirc$ Nothing $\bigcirc$ Stopped using medication(s) $\bigcirc$ Consulted additional source(s) $\bigcirc$ Followed the information from what I thought was the most trustworthy source

Which new source(s) did you use?

Which source did you consider most trustworthy?

Which source did you consider least trustworthy?

neck pain $(n=1)$, or other $(n=1)$. Headache diagnosis was done by a general practitioner $(n=6)$, a headache specialist ( $n$ $=6)$, or another physician $(n=3)$. Two women received the diagnosis by two different physicians (headache center specialist and general practitioner/other practitioner), while 3 did not specify the physician who performed the diagnosis.

\section{Headache presentation and medications before and during pregnancy}

In the 87 women who referred headaches in the year before pregnancy, the median monthly frequency of headache attacks was 2 (IQR, \pm 2.25$)$; 4 women (4\%) referred no headaches, while $9(9 \%)$ did not report this information.

Sixty-two women (62\%) reported headache attacks in the first trimester of gestation $(2 \pm 3.0), 44(44 \%)$ in the second trimester $(2 \pm 1.5)$, and $43(43 \%)$ in the third trimester $(2 \pm$ 1.75). Four women did not give any information about the number of headache crises during pregnancy. As a whole, 71 women referred headache attacks in at least one trimester of their pregnancy. The characteristics of headache attacks before and during pregnancy are described in Table 3.

Among the 87 patients who referred headache before pregnancy, $76(88 \%)$ used drugs to treat the attacks, 9 (10\%) did not use symptomatic medications, and $2(2 \%)$ did not 
Table 2 Characteristics of the study population

\begin{tabular}{ll}
\hline Characteristics & Total $n=100, n(\%$ of $n)$ \\
\hline Age & $11(11)$ \\
$\leq 30$ years & $42(42)$ \\
$31-35$ years & $47(47)$ \\
$\geq 36$ years & \\
Marital status & $97(97)$ \\
Married/in relationship & $3(3)$ \\
Single/other & \\
Status of employment & $71(71)$ \\
Employed & $29(29)$ \\
Student/housewife/other & \\
Level of education & $60(60)$ \\
Academic degree & $34(34)$ \\
High school diploma & $5(5)$ \\
Middle school diploma & $1(1)$ \\
No answer & \\
Sick leave & $7(7)$ \\
Yes & $82(82)$ \\
No & $11(11)$ \\
Not applicable & $70(70)$ \\
Chronic illnesses & $6(6)$ \\
None & $6(6)$ \\
Neuropsychiatric & $20(20)$ \\
Cardiovascular & \\
Other &
\end{tabular}

${ }^{a}$ Epilepsy (3), depression (3), bipolar disorder (1), and insomnia (2)

${ }^{\mathrm{b}}$ Cardiovascular disease (3) and metabolic disorder (3)

${ }^{\mathrm{c}}$ Allergy (10), asthma (1), hypothyroidism (3), celiac disease (2), ulcerative colitis (1), anemia (1), autoimmune urticaria (1), and endometriosis (1)

Fig. 1 Smoking habit and alcohol consumption during pregnancy and, below, relative risk attributed to these behaviors. The perception of risk to the fetus was attributed using a numeric rating scale (NRS) ranging from 0 ("not harmful") to 10 ("very harmful")
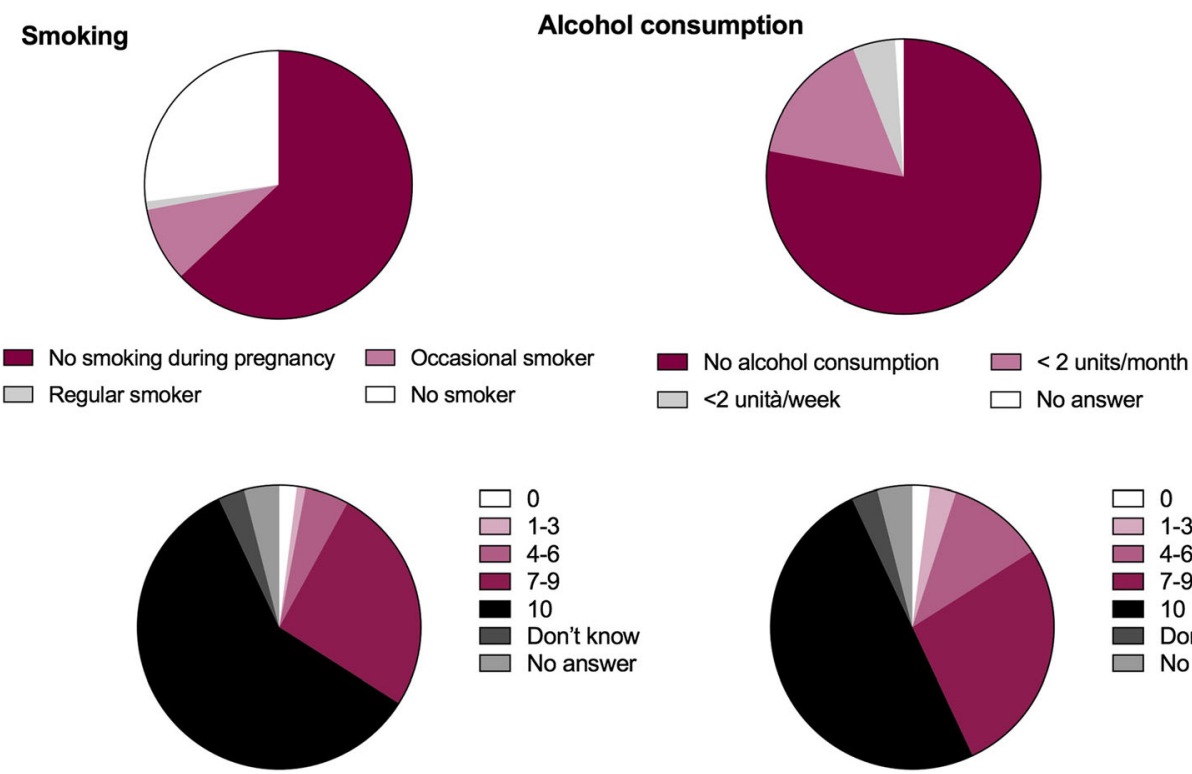

\begin{abstract}
Regular smoker
No smoker
\end{abstract}

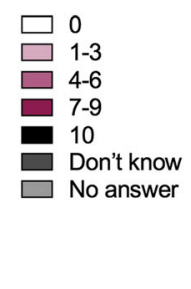

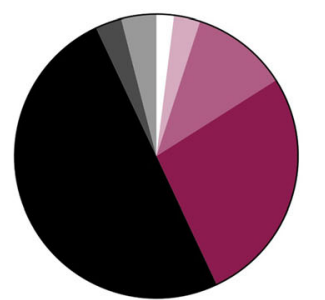

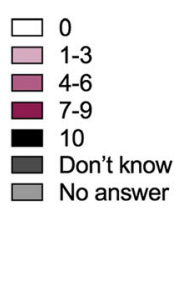

remember this information. The 76 women who treated headache attacks used NSAIDs $(n=52,68 \%)$, paracetamol $(n=$ $25,33 \%)$, analgesic combinations $(n=2,3 \%)$, and triptans $(n$ $=2,3 \%$ ); each participant could indicate the use of more than one pharmacological class to treat the attacks (Fig. 2). Among the 71 women who referred headache attacks in at least one trimester of pregnancy, $37(52 \%)$ used drugs to treat the attacks, 32 (45\%) did not use symptomatic medications, and 2 (3\%) did not remember this information. The 37 women who treated their headaches used paracetamol ( $n=35,95 \%)$, NSAIDs $(n=25 \%)$, and triptans $(n=1,3 \%)$ (Fig. 2$)$.

Just 6 women out of $87(7 \%)$ reported the use of preventive therapy before pregnancy (i.e., 3 used magnesium supplementation, 1 reported homeopathy, and 3 did not specify the treatment) and 8 out of 71 (11\%) during pregnancy (e.g., 4 reported magnesium supplementation, 2 reported iron supplementation, and 2 did not specify the treatment). Before pregnancy, 62 women out of 87 $(71 \%)$ felt that their migraine was treated optimally, 18 (21\%) felt that their migraine was not optimally treated, and $7(8 \%)$ did not remember or did not answer the question. During pregnancy, 56 women out of 71 (79\%) felt that their migraine was treated optimally, $4(6 \%)$ felt that their migraine was not optimally treated, and 11 women (15\%) did not remember or did not answer the question. Twenty-two women among the 87 (25\%) with headaches in the year before pregnancy reported that some adjustments have been made regarding their headache medications (preventive or acute) when they found out they were pregnant. Seventeen women specified that the adjustment consisted in the substitution of NSAIDs (i.e., 8 used ibuprofen, 4 nimesulide, 4 ketoprofen, and 1 aspirin) with paracetamol. Thirty-four women out of 87 (39\%) reported the withdrawal of headache medications during 
Table 3 Characteristics of headache attacks

Before pregnancy During pregnancy

(total $n=87), n(\%$ of $n) \quad($ total $n=71), n(\%$ of $n)$

\begin{tabular}{|c|c|c|}
\hline \multicolumn{3}{|l|}{ Intensity } \\
\hline Mild & $14(16)$ & $18(25)$ \\
\hline Moderate & $36(41)$ & $37(52)$ \\
\hline Intense & $21(24)$ & $11(16)$ \\
\hline Very intense & $16(19)$ & $5(7)$ \\
\hline \multicolumn{3}{|l|}{ Nausea } \\
\hline None & $58(67)$ & $37(52)$ \\
\hline Mild & $19(22)$ & $20(28)$ \\
\hline Intense & $6(7)$ & $10(14)$ \\
\hline Vomiting & $4(4)$ & $4(6)$ \\
\hline \multicolumn{3}{|l|}{ Daily disability } \\
\hline No & $37(42)$ & $29(41)$ \\
\hline Mild & $24(28)$ & $26(37)$ \\
\hline Severe & $17(20)$ & $13(18)$ \\
\hline Confined to bed & $9(10)$ & $3(4)$ \\
\hline \multicolumn{3}{|l|}{ Tolerability } \\
\hline Tolerable & $37(43)$ & $36(51)$ \\
\hline Barely tolerable & $29(34)$ & $27(38)$ \\
\hline Intolerable & $20(23)$ & $8(11)$ \\
\hline
\end{tabular}

pregnancy; 24 reported the withdrawal of a NSAID (i.e., 13 ibuprofen, 6 nimesulide, and 5 ketoprofen), 3 reported the withdrawal of 2 NSAIDs (i.e., 1 ibuprofen and ketoprofen and 2 ibuprofen and nimesulide), 1 reported the interruption of indomethacin-caffeineprochlorperazine, and another reported the interruption of eletriptan. Fifty-one women out of 87 (59\%) reported a responsible for the abovementioned changes in medications, while $36(41 \%)$ did not answer this question. Twenty-eight women reported they autonomously decided these changes, and 20 attributed the responsibility to the practitioner and a woman to the pharmacist. Two women reported more than one responsible for the changes (i.e., a woman the practitioner and the midwife, while another woman answered she decided together with the pharmacist). Seventy-nine women out of 87 (91\%) indicated a responsible for the medical treatment of headache before and during pregnancy. As responsible for the medical treatment of headache, 33 women reported the general practitioner, a woman reported the neurologist, 64 women reported the headache center specialist, 25 women answered "other," and 19 women answered "I am not taking any medication." Among the 25 women who answered "other," 15 reported they were responsible of their own treatment, 2 reported the pharmacist was the responsible, 2 referred the complementary and alternative medicine physicians, a woman referred the gynecologist, and a woman referred the toxicologist. Four women referred more than one responsible for the medical treatment of headache.

\section{Attitude toward use of headache medications}

The attitude of the participants toward use of headache medications before and during pregnancy is reported in Tables 4 and 5 , respectively. The questions about the attitude toward drug use before pregnancy were answered by those participants who suffered headache before pregnancy $(n=87)$. The questions about the attitude toward drug use in pregnancy were answered by those participants who suffered headache during that period $(n=71)$.

Twenty-five subjects reported they had decided not to use symptomatic drugs during pregnancy (10 women specified they did not use paracetamol, 6 ibuprofen, 1 nimesulide, 2 ketoprofen, and 1 rizatriptan; 5 did not give drug details).
Fig. 2 Class of drugs consumed before and during pregnancy to treat headache
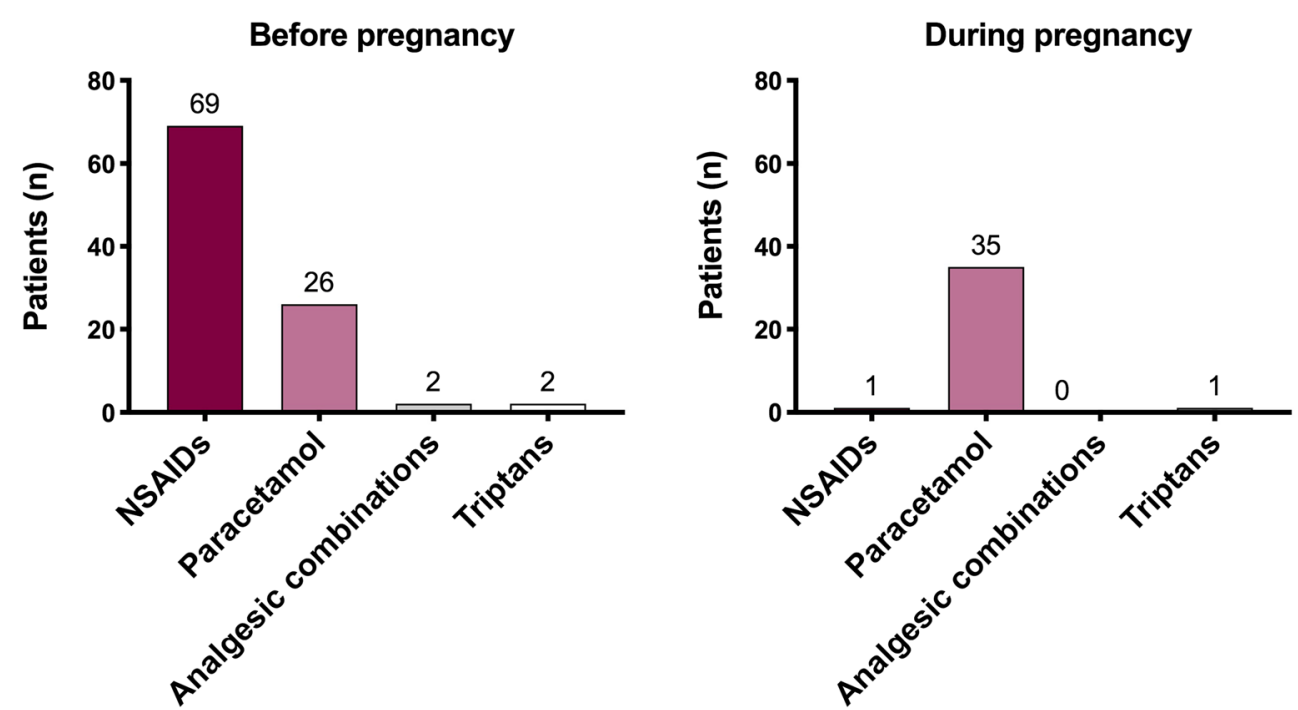


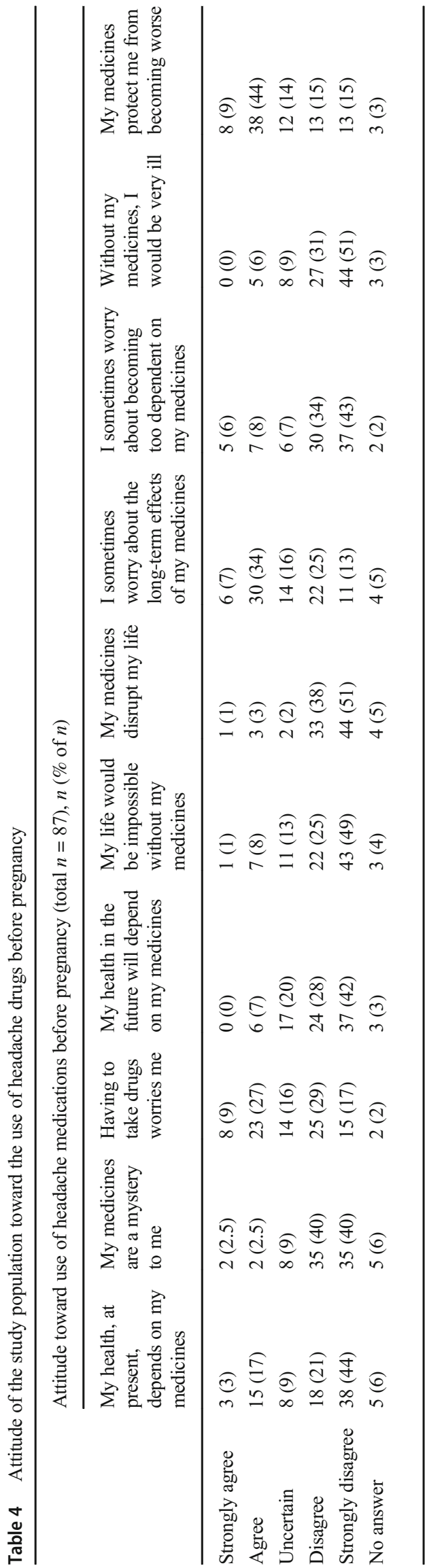

\section{Perception of fetal risk of various drugs and substances during pregnancy}

Answering the question "Among 100 healthy pregnant women, how many do you think will give birth to a child with severe birth defects?," 63 women $(63 \%)$ estimated a mean value of 4.4 children born with severe birth defects, while 37 (37\%) did not report the data (33 did not answer, and 4 answered they did not know).

Eighty participants $(80 \%)$ attributed a low risk (risk class " $0-3$ ") to the use of paracetamol, $11(11 \%)$ an intermediate risk (risk class "4-6"), and $3(3 \%)$ a high risk (risk class "710 "), while 6 did not report a value ( 3 did not answer, and 3 answered they did not know) (Fig. 3, paracetamol risk). Fifteen women (15\%) attributed low risk to the use of ibuprofen in the third trimester of gestation, $20(20 \%)$ intermediate risk, and 46 (46\%) high risk, while 19 did not report this information (17 did not answer, and 2 answered they did not know) (Fig. 3, ibuprofen risk). Seventeen women (17\%) attributed low risk to the use of metoclopramide, 12 (12\%) intermediate risk, and 23 (23\%) high risk, while 48 women did not report this information (43 did not answer, and 5 answered they did not know) (Fig. 3, metoclopramide risk). The largest part of the women did not know triptans and, therefore, was not able to attribute a risk class to these medicines $(n=84$, $84 \%)$. Just 12 participants (12\%) attributed a risk class to triptans; two (2\%) attributed them low risk, $2(2 \%)$ intermediate risk, and $8(8 \%)$ high risk (Fig. 3, triptan risk). Smoking was given low risk by 3 women (3\%), intermediate risk by 5 (5\%), and high risk by $85(85 \%)$. Seven women (7\%) did not attribute any class risk to tobacco smoke (4 did not answer to the question, and 3 answered they did not know) (Fig. 1). Alcohol intake during the first trimester of pregnancy was associated to low risk by 5 women (5\%), intermediate risk by $11(11 \%)$, and high risk by $77(77 \%)$. Seven women (7\%) did not attribute to alcohol any class risk (4 women did not answer, and 3 women answered they did not know) (Fig. $1)$.

\section{Research of information on headache medications before and during pregnancy}

Thirty-one women (36\%) of the 87 suffering from headache before pregnancy reported to have searched information about headache medications prior to the pregnancy and the information sources were represented by physicians $(n=20)$, the Internet $(n=17)$, pharmacy $(n=9)$, friends/family $(n=4)$, and leaflet $(n=1)$. Fifty-one participants $(58 \%)$ reported no information search, while $5(6 \%)$ did not remember or did not report this data (Fig. 4). Information need was similar during pregnancy, with 31 women ( 31 out of $71,44 \%$ ) who referred to have required information to physicians $(n=23)$, the Internet $(n=15)$, pharmacy $(n=3)$, friends/family $(n=2)$, 
Table 5 Attitude of the study population toward the use of drugs for treating headache during pregnancy

Attitude toward the use of headache medications during pregnancy (total $n=71), n(\%$ of $n$ )

\begin{tabular}{lllll}
\hline $\begin{array}{l}\text { I feared that my } \\
\text { headache would get } \\
\text { worse during pregnancy }\end{array}$ & $\begin{array}{l}\text { I used less headache } \\
\text { medication than needed } \\
\text { due to the fact that I was } \\
\text { pregnant }\end{array}$ & $\begin{array}{l}\text { I was worried that my } \\
\text { headache medication } \\
\text { might affect my unborn } \\
\text { child }\end{array}$ & $\begin{array}{l}\text { In my experience, } \\
\text { my doctor had thorough } \\
\text { knowledge of the } \\
\text { medication usage during } \\
\text { pregnancy }\end{array}$ & $\begin{array}{l}\text { Although I suffered } \\
\text { headache in pregnancy, } \\
\text { I refrained from using } \\
\text { any medication, just to } \\
\text { be safe }\end{array}$ \\
$3(4)$ & $31(44)$ & $18(25)$ & $17(24)$ & $21(30)$ \\
$18(25.5)$ & $22(31)$ & $25(35)$ & $36(51)$ & $11(15)$ \\
$12(17)$ & $2(3)$ & $5(7)$ & $3(4)$ & $1(1)$ \\
$18(25.5)$ & $5(7)$ & $11(16)$ & $4(6)$ & $22(31)$ \\
$15(21)$ & $7(10)$ & $8(11)$ & $5(7)$ & $12(17)$ \\
$5(7)$ & $4(5)$ & $4(6)$ & $6(8)$ & $4(6)$
\end{tabular}

and midwives $(n=5)$, and 37 women (52\%) without information needs. Three participants $(4 \%)$ did not remember or did not report this data (Fig. 4). Thirteen women out of $31(42 \%)$ who searched for information during pregnancy reported they have consulted multiple sources. Five of them declared that the information provided was identical among the different sources, 2 reported that the information provided was mostly identical, and 5 referred that the information was more or less identical. Just one woman reported that the information provided was contradictory and she had followed the information from the trust worthiest source according to her opinion (i.e., the physician).

\section{Discussion}

A general, initial comment to our results is that according to the high rate $(51 \%)$ of women suffering from headache among those attending the Maternal and Child Department, this setting should be considered optimal to enroll patients in future studies collecting data about headache and migraine. Going into depth on results, among the participants, $80 \%$ had not received a headache diagnosis before pregnancy and this explains the prevalent use of nonspecific headache medicines. However, some data from this study may suggest that there were many women with migraine among them. First of all, the young age at the onset of a headache that lasts over time with a frequency of $3.7 \pm 5.7$ is strongly suggestive of migraine. Second, $84 \%$ of participants reported moderate to severe headaches before pregnancy which were more than $50 \%$ of the time barely tolerable or intolerable and associated with disability and in 34\% associated with nausea (including vomiting in 4\%) (Table 3). All these features strongly suggest migraine. Third, the number of reported headache attacks decreased during pregnancy, with a marked reduction in the transition from the first to the second trimester (62\% against $44 \%$ ) and then remained stable until the end of pregnancy $(43 \%)$. This tendency in the frequency of headache attacks is typical of the clinical course of migraine during pregnancy, as demonstrated in several previous studies [23].
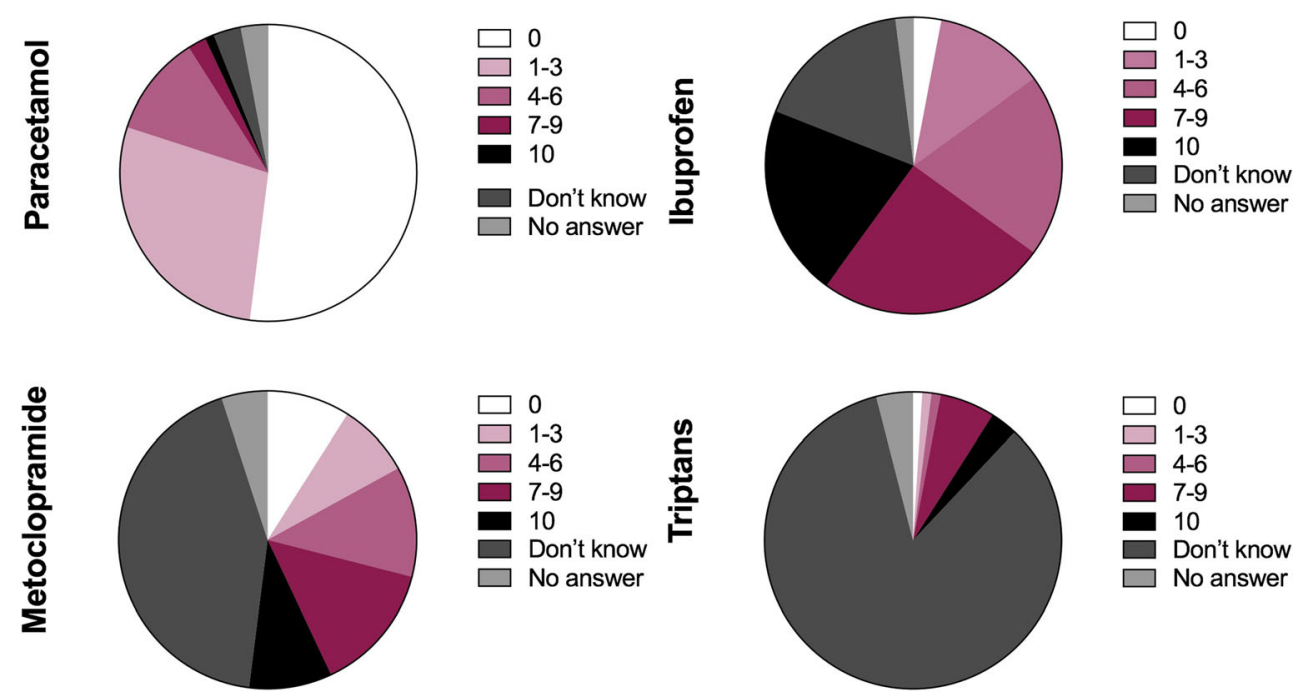
Fig. 4 Source of information about headache drugs before and during pregnancy

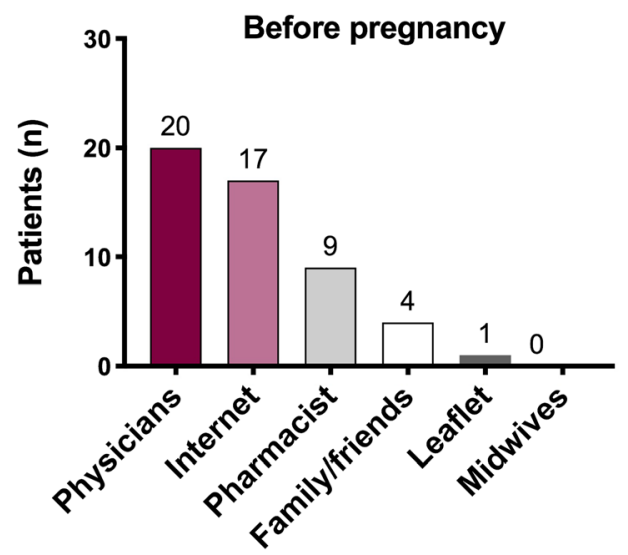

The results show important changes in behavior and therapeutic habits once pregnancy has begun. In fact, before pregnancy, almost all patients ( $88 \%$ ) used to treat headache attacks with drugs, but this percentage decreases significantly during pregnancy when almost half of women (45\%) did not take symptomatic drugs. The reduction in symptomatic intake was also accompanied by a change in the type of class of drugs used. Compared to the previous year, during pregnancy, the proportion of participants who used NSAIDs was reduced from 68 to $5 \%$, while that of those who used paracetamol increased from 33 to $95 \%$ (Fig. 2). The 2 patients who used combinations of analgesics suspended them in pregnancy, as did one of the 2 women who treated their attacks with triptans.

From the analysis of the data regarding the attitude of the patients toward the use of symptomatic drugs before the pregnancy, it emerges a concern about the safety of drugs and, more importantly, the willingness to avoid a possible dependence from them. The majority replied that they did not feel that neither their current health nor their future health depends on drugs (65\% and $70 \%$, respectively), and they did not worry about having to take drugs (46\%) but about their long-term effects (38\%) or the idea of becoming dependent on them (77\%). In addition, participants report that the drugs protect them from getting worse (55\%), but without thinking that without them, they would be very ill $(82 \%)$ or that their life would be impossible (74\%). Despite this, the attitude toward taking drugs in our sample has changed during pregnancy, reflecting a protective interest in the child as demonstrated by the fact that $25 \%$ avoided taking drugs. However, even among those who used symptomatic drugs, most women reported using fewer medicines than they needed because they were pregnant $(75 \%)$ and because they feared they could harm their child $(60 \%)$, although believing that their doctor had a thorough knowledge of these medicines (75\%). Of interest, excluding a minority that was uncertain about the course that the headache would have had (17\%), half of the patients feared a worsening during pregnancy while the other half was not afraid. This last finding is justified by the fact that
$80 \%$ of women suffered from headaches of which they did not know the causes and for which they had not received a diagnosis.

Importantly, both women who have discontinued the use of symptomatic drugs and those who have used them have shown that they have obtained adequate information about their safety during pregnancy. Correctly, $80 \%$ of women attributed to paracetamol a low risk and $11 \%$ an intermediate risk, while with regard to the use of ibuprofen during the third trimester, $46 \%$ indicated a high risk and $20 \%$ an intermediate risk. Regarding the use of metoclopramide, women showed less knowledge about its safety, and in fact among those who expressed an opinion, $33 \%$ attributed a low risk, $23 \%$ an intermediate risk, while $44 \%$ a high risk. Notably, not only triptans are only marginally used, but the majority of patients are not able to attribute a risk to their use, corroborating the hypothesis that these drugs still remain a niche treatment. On the other side, women showed a good knowledge of the effects of some voluptuous habits during pregnancy, attributing a high risk to alcohol intake during the first trimester (77\%) and smoking throughout the pregnancy $(85 \%)$. The final test of the information on pregnancy status comes from the question of what the incidence of newborns with congenital defects in 100 healthy pregnant women was. A percentage of sixtythree of women who answered this question gave an average estimate of 3.4 which fits perfectly in the 3-5\% estimate reported in the literature [24, 25].

Regarding the use of preventive therapy, it was low both before and during pregnancy ( $7 \%$ and $11 \%$ of respondents, respectively) and limited to magnesium supplementation. Magnesium, like most nutraceuticals, has a low level of recommendation according to international migraine treatment guidelines [26]. However, it is commonly used as a selfprescribed anxiolytic agent and in the case of nonspecific headaches and, together with the fact that $80 \%$ of the participants suffered from an ever before diagnosed headache, this could explain why magnesium was the most frequently used preventive treatment. Notably, some patients report the use of 
iron supplementation for headache prevention; also, this result may suggest a scarce knowledge about headache and the need for more education.

Interesting evidence emerges analyzing the need for information on headache drugs, with a change in the attitude before and during pregnancy, although less marked than for the intake of drugs. The percentage of women who searched for information during pregnancy was slightly higher than that in the pre-pregnancy period ( $44 \%$ vs. $36 \%$ ), and the proportion of those that did not look for them earlier decreased slightly during pregnancy ( $58 \%$ vs. $52 \%)$. The main sources of information were doctors and the Internet, with a small prevalence of doctors during pregnancy and the Internet if before pregnancy. However, $42 \%$ of women who sought information during pregnancy reported having consulted several sources (e.g., pharmacists, friends, family, midwives) and that the answers were identical or roughly identical.

\section{Limitations of the study}

This study has some methodological limitations. First, data collection was performed using a self-administrated questionnaire and, although synthetic and with a linear flow of questions, it is possible that there were errors in interpretation and compilation. Second, the retrospective nature of our analysis is per se a drawback and there is the possibility of recall bias, although the timespan is relatively short. Moreover, for each question in the questionnaire, there were a certain number of women who did not provide an answer. Third, this study was conducted in one institution and, consequently, the findings cannot be generalized to all Italian regions.

\section{Conclusions}

There are several noteworthy findings emerging from this study. First, one pregnant woman out of two reported to have suffered from headache, suggesting that maternal departments may be taken into consideration to enroll patients in studies collecting data about headache and migraine. Second, in our cohort, the large majority of patients reporting headache have never received a diagnosis, suggesting the need to both increase the patients' awareness for searching medical attention and ameliorate the diagnostic process. Finally, it is worth noting that pregnancy determines relevant changes in how women treat their headache and, in some extent, how they search for information on drug safety, mostly due to perception of fetal risk of medicines. Accordingly, healthcare providers, in order to optimize headache treatment during pregnancy, should be aware they have to face particular needs of pregnant women with headache, namely pregnancy-oriented education and prescription changes.
Acknowledgements Open access funding provided by Università degli Studi di Roma La Sapienza within the CRUI-CARE Agreement.

Authors' contributions CL: study concept and design, acquisition of the data, analysis and interpretation of the data, and writing of the manuscript; $\mathrm{AN}$ : interpretation of the data and critical revision of the manuscript for intellectual content; EG: acquisition of the data and analysis and interpretation of the data; TS: study supervision and critical revision of the manuscript for intellectual content; GP: critical revision of the manuscript for intellectual content; SB: study concept and design, organizing acquisition of the data, study supervision, interpretation of the data, and critical revision of the manuscript for intellectual content.

Data availability The dataset generated and analyzed during the current study is available from the corresponding author on reasonable request.

\section{Compliance with ethical standards}

Conflict of interest The authors declare that they have no conflict of interest.

Ethical approval The study was approved by the local Institutional Ethics Committee on Clinical Research (Comitato Etico Regione Toscana Area Vasta Centro, Florence).

Consent for publication Written informed consent for publication was obtained from all participants before study entry.

Open Access This article is licensed under a Creative Commons Attribution 4.0 International License, which permits use, sharing, adaptation, distribution and reproduction in any medium or format, as long as you give appropriate credit to the original author(s) and the source, provide a link to the Creative Commons licence, and indicate if changes were made. The images or other third party material in this article are included in the article's Creative Commons licence, unless indicated otherwise in a credit line to the material. If material is not included in the article's Creative Commons licence and your intended use is not permitted by statutory regulation or exceeds the permitted use, you will need to obtain permission directly from the copyright holder. To view a copy of this licence, visit http://creativecommons.org/licenses/by/4.0/.

\section{References}

1. Diamond S, Bigal ME, Silberstein S, Loder E, Reed M, Lipton RB (2007) Patterns of diagnosis and acute and preventive treatment for migraine in the United States: results from the American Migraine Prevalence and Prevention Study. Headache 47:355-363. https:// doi.org/10.1111/j.1526-4610.2006.00631.x

2. Karli N, Baykan B, Ertaș M, Zarifoğlu M, Siva A, Saip S, Özkaya $\mathrm{G}$ (2012) Impact of sex hormonal changes on tension-type headache and migraine: a cross-sectional population-based survey in 2, 600 women. J Headache Pain 13:557-565. https://doi.org/10.1007/ s10194-012-0475-0

3. Maggioni F, Alessi C, Maggino T, Zanchin G (1997) Headache during pregnancy. Cephalalgia 17:765-769. https://doi.org/10. 1046/j.1468-2982.1997.1707765.x

4. Pfaffenrath V, Rehm M (1998) Migraine in pregnancy: what are the safest treatment options? Drug Saf 19:383-388. https://doi.org/10. 2165/00002018-199819050-00005

5. Sances G, Granella F, Nappi RE, Fignon A, Ghiotto N, Polatti F, Nappi G (2003) Course of migraine during pregnancy and 
postpartum: a prospective study. Cephalalgia 23:197-205. https:// doi.org/10.1046/j.1468-2982.2003.00480.x

6. Aubé M (1999) Migraine in pregnancy. Neurology 53:S26-S28

7. Wabnitz A, Bushnell C (2015) Migraine, cardiovascular disease, and stroke during pregnancy: systematic review of the literature. Cephalalgia 35:132-139. https://doi.org/10.1177/ 0333102414554113

8. Gladstone JP, Eross EJ, Dodick DW (2004) Migraine in special populations. Treatment strategies for children and adolescents, pregnant women, and the elderly. Postgrad Med 115(39-44):47-50

9. Bloor M, Paech M (2013) Nonsteroidal anti-inflammatory drugs during pregnancy and the initiation of lactation. Anesth Analg 116:1063-1075. https://doi.org/10.1213/ANE.0b013e31828a4b54

10. Lind JN, Interrante JD, Ailes EC, Gilboa SM, Khan S, Frey MT, Dawson AL, Honein MA, Dowling NF, Razzaghi H, Creanga AA, Broussard CS (2017) Maternal use of opioids during pregnancy and congenital malformations: a systematic review. Pediatrics 139: e20164131. https://doi.org/10.1542/peds.2016-4131

11. Yakoob MY, Bateman BT, Ho E, Hernandez-Diaz S, Franklin JM, Goodman JE, Hoban RA (2013) The risk of congenital malformations associated with exposure to $\beta$-blockers early in pregnancy: a meta-analysis. Hypertension 62:375-381. https://doi. org/10.1161/HYPERTENSIONAHA.111.00833

12. Alsaad AMS, Chaudhry SA, Koren G (2015) First trimester exposure to topiramate and the risk of oral clefts in the offspring: a systematic review and meta-analysis. Reprod Toxicol 53:45-50. https://doi.org/10.1016/j.reprotox.2015.03.003

13. Polifka JE (2012) Is there an embryopathy associated with firsttrimester exposure to angiotensin-converting enzyme inhibitors and angiotensin receptor antagonists? A critical review of the evidence. Birth Defects Res A Clin Mol Teratol 94:576-598. https:// doi.org/10.1002/bdra.23027

14. Brandlistuen RE, Ystrom E, Nulman I, Koren G, Nordeng H (2013) Prenatal paracetamol exposure and child neurodevelopment: a sibling-controlled cohort study. Int J Epidemiol 42:1702-1713. https://doi.org/10.1093/ije/dyt183

15. Liew Z, Ritz B, Rebordosa C, Lee PC, Olsen J (2014) Acetaminophen use during pregnancy, behavioral problems, and hyperkinetic disorders. JAMA Pediatr 168:313-320. https://doi. org/10.1001/jamapediatrics.2013.4914

16. Ystrom E, Gustavson K, Brandlistuen RE, Knudsen GP, Magnus P, Susser E, Davey Smith G, Stoltenberg C, Surén P, Håberg SE, Hornig M, Lipkin WI, Nordeng H, Reichborn-Kjennerud T (2017) Prenatal exposure to acetaminophen and risk of ADHD. Pediatrics 140:e20163840. https://doi.org/10.1542/peds.2016-3840
17. Fan G, Wang B, Liu C, Li D (2017) Prenatal paracetamol use and asthma in childhood: a systematic review and meta-analysis. Allergol Immunopathol (Madr) 45:528-533. https://doi.org/10. 1016/j.aller.2016.10.014

18. Marchenko A, Etwel F, Olutunfese O, Nickel C, Koren G, Nulman I (2015) Pregnancy outcome following prenatal exposure to triptan medications: a meta-analysis. Headache 55:490-501. https://doi. org/10.1111/head.12500

19. Lewis JB, Frohman EM (2001) Diagnosis and management of headache. Obstet Gynecol Clin North Am 28:205-24, v. doi: https://doi.org/10.1016/s0889-8545(05)70197-2

20. Bohio R, Brohi ZP, Bohio F (2016) Utilization of over the counter medication among pregnant women; a cross-sectional study conducted at Isra University Hospital, Hyderabad. J Pak Med Assoc 66:68-71

21. Amundsen S, Øvrebø TG, Amble NMS, Poole AC, Nordeng H (2016) Use of antimigraine medications and information needs during pregnancy and breastfeeding: a cross-sectional study among 401 Norwegian women. Eur J Clin Pharmacol 72:1525-1535. https://doi.org/10.1007/s00228-016-2127-9

22. Headache Classification Committee of the International Headache Society (2013) The International Classification of Headache Disorders, 3rd edition. Cephalalgia 33:629-808. https://doi.org/ $10.1177 / 0333102413485658$

23. Negro A, Delaruelle Z, Ivanova TA, Khan S, Ornello R, Raffaelli B, Terrin A, Reuter U, Mitsikostas DD, European Headache Federation School of Advanced Studies (EHF-SAS) (2017) Headache and pregnancy: a systematic review. J Headache Pain 18:106. https://doi.org/10.1186/s10194-017-0816-0

24. Feldkamp ML, Carey JC, Byrne JLB, Krikov S, Botto LD (2017) Etiology and clinical presentation of birth defects: population based study. BMJ 357:j2249. https://doi.org/10.1136/bmj.j2249

25. Centers for Disease Control and Prevention (CDC) (2008) Update on overall prevalence of major birth defectsAtlanta, Georgia, 1978-2005. MMWR Morb Mortal Wkly Rep 57(1):1-5

26. Steiner TJ, Jensen R, Katsarava Z, Linde M, MacGregor EA, Osipova V, Paemeleire K, Olesen J, Peters M, Martelletti P (2019) Aids to management of headache disorders in primary care (2nd edition): on behalf of the European Headache Federation and Lifting The Burden: the Global Campaign against Headache. J Headache Pain 20:57. https://doi.org/10.1186/s10194-018-0899-2

Publisher's note Springer Nature remains neutral with regard to jurisdictional claims in published maps and institutional affiliations. 